Revista Vernáculo, n. 27, $1^{\circ}$ sem./2011

\title{
ILUMINISMO OU ILUMINISMOS?
}

\author{
Flávio Renato de Aguiar Lopes*
}

Resumo: O presente artigo propõe que o Iluminismo não foi um movimento homogêneo, ocorrido somente na França, conforme defendem alguns historiadores e grande parte do material didático disponível. A perspectiva dominante no ensino limita o conhecimento dos estudantes de história, pois desconsidera a possibilidade de se conhecer como o Iluminismo se originou em outras nações. Em um primeiro momento, estabelecemos uma relação entre ensino e Iluminismo, mostrando a partir da análise de um livro didático e de questões extraídas de vestibulares como esse assunto é tratado no âmbito da educação básica. Na sequência, trazemos à discussão o conceito de Iluminismo, focando as características comuns de todas as tendências desse movimento intelectual. Encerrado esse debate, apresentamos as novas correntes que defendem a existência de uma pluralidade de Iluminismos e destacamos o Português para dar suporte a essa análise. Com esse trabalho, pretendemos mostrar que existiram diferentes tendências no âmbito do Iluminismo, bem como apontar possíveis melhorias da discussão desse assunto em sala de aula.

Palavras-chave: Iluminismo; ensino; Iluminismo Português.

Abstract: This article argues that the Enlightenment was not a homogeneous movement, occurred only in France, as some historians argue, and much of the teaching material available. The dominant perspective on teaching limits students' knowledge of history, because it ignores the possibility of knowing how the Enlightenment originated in other nations. At first, we establish a relationship between education and Enlightenment, showing the analysis of a textbook and

* Graduando em História pela Universidade de Brasília (UnB). 
vestibular issues as extracted from the subject is treated as part of basic education. Following, we bring to the discussion the concept of Enlightenment, focusing on the common characteristics of all the intellectual trends of this movement. Ended this debate, we present the new trends that advocate the existence of a plurality of Enlightenment and highlight the Portuguese to support this analysis. With this work, we intend to show that there were different tendencies within the Enlightenment, and to identify possible improvements of the discussion of this subject in the classroom.

Keywords: Enlightenment; teaching; Portuguese Enlightenment. 


\title{
ILUMINISMO OU ILUMINISMOS?
}

\author{
Flávio Renato de Aguiar Lopes
}

\section{Introdução}

Neste trabalho, pretendemos mostrar que o Iluminismo não foi um movimento de ideias únicas, homogêneo, que ocorreu somente na França, conforme defendem alguns historiadores e grande parte do material didático disponível. A perspectiva que domina o ensino limita o conhecimento dos estudantes de história, pois não leva em consideração a possibilidade de se conhecer como se formou o Iluminismo em outras nações, bem como suas particularidades.

Assim, iniciamos o presente estudo estabelecendo uma relação entre escola e Iluminismo, mostrando a partir da análise de um livro didático e de questões extraídas de vestibulares como o assunto Iluminismo é tratado no âmbito da educação básica. $\mathrm{Na}$ sequência, trazemos à discussão o conceito de Iluminismo (mesmo sabendo da existência de outros movimentos iluministas, procuramos conceituar de uma maneira geral o Iluminismo), focando as características comuns de todas as tendências desse movimento intelectual. Encerrado esse debate, apresentamos as novas correntes que defendem a existência de uma pluralidade de 
Iluminismos e destacamos o Português para dar suporte a essa análise.

A nossa intenção com essa proposta de trabalho é mostrar que existiram diferentes tendências no âmbito do Iluminismo, bem como apontar possíveis melhorias da discussão desse assunto em sala de aula.

\section{Relação Escola X Iluminismo}

O ensino sobre o Iluminismo, de um modo geral, é feito nas escolas de maneira simplista, genérica e, até mesmo, equivocada. Isso se reflete em alguns livros didáticos que dão pouquíssimo destaque ao Iluminismo em suas páginas. Geralmente, apresentam-se, em poucas páginas, detalhes escassos sobre as suas características e seus principais pensadores.

Além disso, o ensino tradicional tende a transmitir que somente existiu um tipo de Iluminismo na Europa, o francês. Com isso, os autores de livros didáticos ignoram as diferentes expressões do pensamento Iluminista em outros países europeus, como na Alemanha, na Itália, em Portugal, por exemplo.

Para exemplificar, analisamos o livro didático "História da Civilização Ocidental" (PEDRO \& LIMA, 2004), o qual afirma que os ideais iluministas influenciaram diretamente algumas Revoluções, o que tem sido questionado por alguns historiadores, mais 
recentemente. ${ }^{135}$ Segundo os autores, "A revolução intelectual fazia parte do processo de transformações por que passavam as sociedades europeia e americana." (PEDRO \& LIMA, 2004, p. 242)

Os pensadores do Iluminismo contribuíram para os fundamentos teóricos e práticos das revoluções que já estavam acontecendo ou iriam acontecer, como a Revolução Americana, que resultou na independência dos Estados Unidos, e a Revolução Francesa, que resultou na derrubada violenta do absolutismo e da nobreza. (PEDRO \& LIMA, 2004, p. 242 - grifos meus).

Nesse mesmo livro didático, os autores consideraram a obra Enciclopédia, apresentada como o marco das ideias iluministas na França (novamente a "exclusividade" da França), desprezando a importância de obras como "Do espírito das leis" (1748), de Montesquieu; "Émile" e "Do contrato social" (1762), de Rousseau. Por conta disso, os estudantes adquirem uma interpretação limitada do Iluminismo: "o maior veículo de difusão das ideias iluministas na França foi a Enciclopédia, obra que pretendia abranger todo o conhecimento filosófico e científico da época. Com cerca de trezentos colaboradores, reunia a elite intelectual francesa do século XVIII." (2003, p. 240)

Por causa dessas - e outras - limitações teóricas dos livros didáticos e também dos professores do Ensino Médio, os estudantes

${ }^{135}$ Ver DARTON, 2005; OUTRAM, 1995. 
saem da escola com um conhecimento escasso acerca desse importante movimento filosófico-intelectual.

Uma das razões para essa discussão simplificada nas escolas pode estar relacionada ao tempo limitado do professor para ensinar um conteúdo tão vasto. Além disso, as provas para vestibulares também tendem a abordar o Iluminismo como um movimento único, como podemos perceber nas questões abaixo:

(URCA/CE) Questão 3: O Iluminismo produziu ideias que serviram de base ideológica para as Revoluções Burguesas dos séculos XVIII e XIX. Seus pensadores escreveram tratados filosóficos, econômicos e políticos. Entre eles, o Barão de la Brède e de Montesquieu (1689 - 1755), mais conhecido somente por Montesquieu. Assinale a alternativa que diz respeito ao seu pensamento político.

(UFF/RJ) Questão 11: A Revolução Francesa foi obra coletiva com a participação de todos os setores da sociedade francesa, de nobres a camponeses, passando por burgueses e operários. Essa dimensão coletiva também esteve presente nas idéias que deram base à revolução, como o Iluminismo, sistema de pensamento oriundo das reflexões dos intelectuais franceses. Esses dois aspectos estão presentes numa obra que junta todos os conhecimentos novos, práticos e teóricos.

Assinale a alternativa que indica a obra que denota o caráter renovador da Revolução Francesa. 
A - A Enciclopédia dirigida por Voltaire e Rousseau, que estabelecia as regras de organização da nova sociedade francesa, com destaque especial para o elogio aos modos de vida da nobreza, no que diz respeito à educação e aos costumes refinados.

B - A Declaração dos Direitos do Homem e do Cidadão, que anunciava a possibilidade da revolução resultar de um acordo entre os filósofos das Luzes e o Antigo Regime, com o intuito de manter a ordem nos campos e nas cidades.

C - A Declaração Civil do Clero, que cortava radicalmente as ligações com o feudalismo e introduzia um novo estatuto para os trabalhadores rurais, garantindo-lhes a propriedade das terras da nobreza.

D - A Enciclopédia dirigida por Diderot e D'Alembert, que condensava todas as novas visões sobre o mundo, o homem e a sociedade. Servia de guia para a oposição aos valores do Antigo Regime.

E - A Declaração dos Direitos do Homem e do Cidadão, que preconizava a manutenção da autoridade da nobreza sobre todas as terras da França e dos burgueses sobre as cidades, dividindo o território em duas grandes partes para manter os ideais da Revolução.

Gabarito: D

Nos próprios Parâmetros Curriculares Nacionais (PCNs) um dos documentos norteadores da educação brasileira - não há 
uma abordagem clara de como o(s) Iluminismo(s) devem ser discutidos em sala. Uma referência - ainda assim superficial - sobre o conteúdo é feito nas Orientações Curriculares para o Ensino Médio (BRASIL, 2006):

$\mathrm{O}$ recurso à Filosofia, por sua vez, enriquece e amplia o conceito, especialmente no que se refere à idéia de cultura como formação advinda da "paidéia" (ligada à educação) e da cultura humanista, renascentista e iluminista. $\mathrm{Na}$ articulação dessas abordagens (histórica, antropológica e filosófica), o conceito de cultura pode alcançar maior abrangência e significado.

Como apresentado, o ensino traz de maneira genérica e superficial as importantes contribuições iluministas para a sociedade ocidental, o que não leva o aluno a refletir acerca dessas contribuições para o seu dia a dia.

Esse quadro precisa, pois, mudar. E o primeiro passo é mostrar que o que é tradicionalmente considerado "Iluminismo" se configura, na verdade, como uma variedade de movimentos intelectuais e internos e debates que ocorreram na Europa. Nesse sentido, a França não seria mais vista como o único Estado a abarcar os ideais iluministas, mas, sim, como o melhor exemplo de onde essas ideias foram desenvolvidas e divulgadas.

Antes de refletirmos mais acerca do ensino, vamos expor, na próxima seção, algumas linhas gerais do que foi o "Iluminismo", e por que defendemos um ensino plural desse movimento. 


\section{O Movimento Iluminista}

O significado do nome "Iluminismo" não é algo fácil de definir para os historiadores e filósofos, pois essa palavra contém várias interpretações e sentidos diferentes, variando conforme o campo do conhecimento em que ela é aplicada. Numa acepção mística, por exemplo, ela se refere à revelação divina; já no racionalismo, ela remete à valorização da iluminação das ideias, nacionais contrapondo os séculos anteriores que seriam as "trevas", com a iluminação trazida pelos pensadores do século XVIII.

O historiador Francisco José Falcon (2009) também defende que não existe um consenso entre os especialistas sobre o significado do nome do Iluminismo:

O problema do vocabulário das "Luzes" é ainda uma questão em aberto. Não basta estudar cada palavra em si mesma; é preciso situá-la filológica e historicamente, nacionalmente e internacionalmente. A rede de significações que constituem o seu campo semântico não é mera reprodução ou reflexo de uma realidade histórica, mas é uma reação a essa realidade. Entre uma coisa e outra há um espaço mental, maior ou menor, tendente à contestação da própria realidade. Tal é o caso francês, por isso mesmo considerado "clássico": distancia e reação convertem-se aí em crítica violenta ao existente.

Quer na filosofia, com o platonismo e o neoplatonismo, quer na esfera religiosa, com o judaísmo e o cristianismo, a luz é sempre imagem ou símbolo que significa verdade ou conhecimento verdadeiro. A iluminação mística cristão, 
baseada na revelação divina, foi relida e secularizada pelo pensamento das "Luzes".

Tal apropriação da metáfora das "Luzes" pelos iluministas, opondo as "Luzes" às “Trevas" das superstições, dos erros e da ignorância dos séculos precedentes, possuía também seus riscos. Pretendendo veicular novos sentidos através da antiga metáfora, os "filósofos" não podiam impedir que, entretanto, para muitos, o sentido tradicional se mantivesse vivo.

Sabemos agora que o Iluminismo tanto pode significar a doutrina dos que acreditam na "iluminação interior" ou mística, a qual para outros constituía uma espécie de manifestação "irracionalista", quanto, justo o oposto, Iluminismo é sinômino de "filosofia das luzes", isto é, da chamada "iluminação racional". (FALCON, 2009, p.15-17, passim)

Os estudiosos concordam que o Iluminismo foi um movimento intelectual europeu do século XVIII, que reuniu os maiores pensadores e filósofos da época em diversos países.

Os racionalistas influenciaram os pensadores iluministas no que se refere à valorização da razão, pois se utilizavam da razão e da ciência para explicar praticamente todos os acontecimentos do homem. Esse preceito será muito utilizado por boa parte dos pensadores iluministas, que criticaram as explicações de mundo com base na religião.

Os filósofos tinham como objetivos gerais para o movimento: 1) a luta contra qualquer tipo de limitação ao conhecimento humano, 
como o que era feito pela Igreja cristã (embora os iluministas, em sua maioria, não se consideravam ateus, acreditando, inclusive, na Divina Providência, que está relacionada à intervenção de Deus na Terra como um castigo); 2) a busca incessante pela felicidade terrena, que explica o fato de alguns pensadores iluministas valorizarem as cortes, e o luxo; 3) a valorização da razão, pois, para os iluministas, ela traria o progresso para a humanidade; 4) o questionamento da Natureza humana: boa ou ruim? uniforme e imutável? quais seriam as "leis" que a governavam?

Estes aspectos são legados deixados pelos iluministas para os séculos posteriores. A felicidade terrena, para exemplificar, de tão relevante está colocada na Declaração de Independência dos Estados Unidos, de 1776:

Consideramos estas verdades autoevidentes: que todos os homens são criados iguais, dotados pelo seu Criador de certos Direitos inalienáveis, que entre estes estão a Vida, a Liberdade e a busca da Felicidade. - Que para assegurar esses direitos, Governos são instituídos entre os Homens, derivando seus justos poderes do consentimento dos governadores. - Que, sempre que qualquer Forma de Governo se torne destrutiva desses fins, é Direito do Povo alterá-la ou aboli-la, e instituir novo Governo, assentando sua fundação nesses princípios e organizando os seus poderes da forma que lhe pareça mais conveniente para a realização da sua Segurança e Felicidade. (HUNT, 2010, p. 219-220) 
Por sua vez, o destaque à racionalidade humana foi muito bem aceita pelas comunidades acadêmicas científicas do século XIX, pois valorizava a ciência, e descobertas nas diversas áreas do conhecimento humano.

Em resumo, embora haja uma aparente unidade nas características gerais, o Iluminismo ocorreu em vários países da Europa e quase que ao mesmo tempo em todos, de formas variadas. Essa vasta expansão tem provocado recentemente muitos questionamentos recentemente sobre, por exemplo, a delimitação geográfica e cronológica (o movimento foi restrito a alguns poucos países europeus? começou e terminou no século XVIII?); as origens ideológicas; etc.

Os trechos abaixo ilustram essa diversidade de perguntas e teorias sobre o(s) Iluminismo(s):

Mas só foi quando os herdeiros intelectuais, os philosophes, ocuparam o terreno e lançaram-se à campanha que o Iluminismo emergiu como a causa, com militantes e um programa. Seus partidários forjaram sua identidade coletiva em Paris durante as primeiras décadas do século XVIII. À medida que o movimento ganhou força, ele se espalhou, e à medida que se espalhou, sofreu mudanças, adaptando-se a outras condições e incorporando outras idéias. Mas não chegou a toda, nem cobriu todo o espectro da vida intelectual. (DARNTON, 2005, p. 20 e 21).

O Iluminismo surgiu de uma grande crise durante os últimos anos do reinado de Luís XIV. (DARNTON, 2005, p. 23) 
A única resposta possível é que o Iluminismo é uma invenção. Uma invenção de intelectuais, sobre intelectuais, para intelectuais, um conceito criado por intelectuais do século XVIII que é mantido vivo por sucessivas gerações de intelectuais. (COSTA, 1990, p. 34).

E o Iluminismo, seria uma tendência transepocal, uma tendência que, certamente, teve na Ilustração a sua realização histórica mais rica, mas que não começou no século XVIII, nem terminou no século XVIII. O Iluminismo, nesse sentido, seria definido como uma tendência de contestação da existência, através da razão e da crítica. Uma crítica racional do poder, dos dogmas e superstições que estão a serviço do poder. (...). Começou com os Gregos. (ROUANET, 1992, p.14)

O absolutismo e as condições de produção do período mercantilista já não atendiam às exigências provocadas pelas novas forças produtivas da Revolução Industrial. $\mathrm{O}$ Iluminismo (ou Ilustração) vinha ao encontro dos novos anseios, criticando o absolutismo, a religião e o mercantilismo como elementos limitados do avanço da sociedade como um todo. Teve intensa repercussão em toda a Europa e nas Américas, inspirando a independência das colônias inglesas na América do Norte (os Estados Unidos) e as rebeliões anticoloniais no Brasil (Inconfidência Mineira, Revolta dos Alfaiates). (PEDRO \& LIMA, 2004, p. 239 e 240).

Mas, por quais motivos o Iluminismo foi um movimento basicamente europeu, e não aconteceu um movimento de intelectuais em outras localidades, como nas próprias colônias europeias? 
Para alguns estudiosos, o Iluminismo não conseguiu se desenvolver fora da Europa, pois nesses lugares os pensadores e filósofos não tinham uma infraestrutura de qualidade para desenvolver as suas ideias (bibliotecas, imprensa), e também esses pensadores tinham um público bem menor em relação ao europeu. Esses fatores limitavam ainda mais o desenvolvimento de seus trabalhos intelectuais. Esses problemas foram detectados nas colônias europeias, e em países que não passaram pelos processos de transformações sociais e econômicas, pelos quais muitos países da Europa passaram:

Nesses países, os intelectuais não apenas tinham um público menor: também lhes faltava o aparato intelectual (ou se quiserem infra-estrutura) - dinheiro, biblioteca, imprensas, livraria etc. -, que os intelectuais franceses e ingleses tinham ao seu dispor. Isso explica o papel secundário como propagandistas de idéias que os intelectuais das áreas menos desenvolvidas do mundo tiveram de desempenhar. Evidentemente, pode-se encontrar nas colônias da Espanha e de Portugal, indivíduos com competência para extrair de sua própria experiência conclusões semelhantes às dos filósofos. Mas eles encontravam um limite nas suas sociedades: no pequeno tamanho do público, na escassez de bibliotecas, escolas, livrarias etc. Faltando-lhes as condições que na Europa estavam criando possibilidades de profissionalização, eles estavam condenados a depender dos mercados europeus de idéias. Seu ponto de referência estava inevitavelmente deslocado (residia fora), mesmo nos momentos de mais ardente nacionalismo. No entanto é tanto correto dizer que 
eles viam a realidade à sua volta através das lentes da Ilustração através das lentes da sua experiência cotidiana. E como suas experiências diferiam consideravelmente, eles criaram muitas leituras da Ilustração. (COSTA, 1990, p.38).

$\mathrm{Na}$ próxima seção, aprofundamos o debate acerca da pluralidade de iluminismos.

\section{Iluminismo ou Iluminismos?}

Durante boa parte dos séculos XIX e XX, até aproximadamente 1970, o Iluminismo foi interpretado por historiadores do porte de Gay (1966), Hazard (1946) e Cassirer (1932) como um movimento restrito à França e homogêneo em seu conjunto de ideias. Os especialistas dos séculos XIX e XX fundamentavam os argumentos utilizados pelos movimentos pósRevolução Francesa e pelos movimentos liberais do século XIX com base nas ideias do Iluminismo. Essa adaptação causou algumas interpretações errôneas, como a tradução equivocada de Aufklarüng, o Iluminismo alemão, na perspectiva de Kant, cujo sentido remete a uma ação em processo; para um sentido de ideia já acabada. Carvalho (2008) nos mostra que:

Esta é a maneira como Gay iniciou o livro The Enlightenment, apresentando o Iluminismo como uma unidade, como um conjunto de idéias harmoniosas, elaboradas por grupo de grandes pensadores, no qual as 
pequenas divergências não chegaram a afetar a unidade. A explicação do autor, muito utilizada entre os anos 1960 e 1970, não foi pioneira nesse tipo de abordagem acerca do Iluminismo, tendo apenas dado continuidade a uma tradição historiográfica oitocentista, que, no século $\mathrm{XX}$, teve no filósofo Ernst Cassirer e no historiador francês Paul Hazard duas grandes referencias (Chaunu, 1995: 277; Outram, 1995: 3-4).

Tanto na síntese de Cassirer quanto na de Hazard, o pensamento Iluminista não foi visto em uma perspectiva plural, isto é, considerando-se as especificidades, os debates, as diferenças e as tensões inerentes a esse movimento de idéias. O Iluminismo foi concebido como uma tendência intelectual do Setecentos baseada em conjunto de idéias aparentemente harmônicas - desenvolvido por grupo de grandes pensadores - em sua maioria franceses uniformizado, metonimicamente, como padrão para a Europa setentista. Esse ponto de vista pode ser inferido da seguinte colocação de Cassierer: "O pensamento do século XVIII (...) corresponde em suma ao desenvolvimento analítico que é, sobretudo, um fenômeno francês" (1997: 50).

O conceito de Iluminismo presente no pensamento de alguns filósofos setecentistas, entretanto, não foi o mesmo divulgado nas sínteses históricas realizadas no decurso do século XX. Nesse interregno, a noção original sofreu revisões e reelaborações, sendo ideológicos dos intelectuais dos contextos pós-Revolução Francesa e liberal do século XIX. De acordo com Dorinda Outram, as discussões em torno do significado do Iluminismo, iniciadas em pleno ambiente 
intelectual do Setecentos, permanecem sem esmorecimento até a atualidade. Alguns filósofos contemporâneos às Luzes, como Moses Mendelssohn (1729-1786) e Immanuel Kant (1724-1804), entenderam o Iluminismo - denominado Aufklärung no idioma alemão - diferentemente da forma como esse movimento de idéias foi interpretado em algumas obras filosófico-históricas clássicas do século XX, associandoo mais a noção de "processo" do que à de "projeto acabado" (Outram, 1995: 1-2). (CARVALHO, 2008, p. 30-32, passim)

Apesar de as críticas ao Iluminismo como movimento único e centrado na França terem se iniciado por volta de 1970, ainda hoje encontramos os livros didáticos se limitando a afirmar que se trata de um movimento homogêneo.

\subsection{Quando e por que as interpretações sobre o Iluminismo começaram a se modificar?}

As modificações sobre as interpretações do Iluminismo começaram a partir de 1970, no momento em que os historiadores iniciaram uma nova leitura sobre a historiografia do Iluminismo. Isso aconteceu devido às pesquisas realizadas no âmbito do estudo das ideias da sociedade do século XVIII, que tinha o objetivo de pesquisar como os ideais iluministas foram difundidos e recebidos pela população de sua época. Ademais, as interpretações e traduções de termos passaram pelas análises de fontes da época antes de passarem pelas traduções. 
As consequências dessas alterações foram sentidas pelos próprios especialistas, que passaram a entender o Iluminismo não mais como um movimento homogêneo, um bloco único de ideias iguais, sem ramificações, centrado quase que exclusivamente na França; agora passava a ser interpretado como um movimento heterogêneo, com várias ramificações com algumas ideias em comum, mas longe de serem uniformes.

São exemplos de historiadores que se utilizaram dessa busca das fontes mais confiáveis para realizar essas modificações no movimento iluminista: Robert Darton, Dorinda Outram.

Essas reformulações no estudo do Iluminismo, ocorridas no final do século $\mathrm{XX}$, foram importantes, trazendo muitas consequências para o mundo acadêmico, como demonstra os historiadores Flávio Carvalho (2008) e Tereza Kirschner (2009):

A dilatação da área geográfica do Iluminismo foi, na concepção de Dorinda Outram, um processo decorrente do revisionismo historiográfico iniciado a partir dos anos 1970. Nessa época, os historiadores começaram a se dedicar ao estudo social das idéias, procurando descobrir a maneira como os conhecimentos de cunho iluminista foram difundidos e acolhidos pela sociedade. Os pesquisadores passaram a analisar o impacto desses saberes nas várias regiões do globo, assim como nas várias camadas sociais (Outram, 1995: 6-8). Isso suscitou uma série de questões novas aos historiadores do Iluminismo, extrapolando o horizonte das Luzes até então deslumbrado por intermédio dos modelos interpretativos de Cassirer, Hazard e Gay. De 
acordo com o historiador norte-americano Franklin Le Van Baummer, essas investigações recentes, baseadas em novas abordagens e em novos problemas, transformaram o Iluminismo em um "alvo móvel", permeado por dúvidas, mudanças de espírito, divisões internas, temporalidades distintas e por características peculiares, conforme o contexto dos vários países (Baumer, 1990: 164).

Essa guinada historiográfica desequilibrou, gradualmente, a coerências interna da síntese Iluminista, até então bastante aceita entre os historiadores, de modo que a balança da consciência historiográfica começou a pender em favor da sua reavaliação. Assim, as pesquisas acerca do Iluminismo, até então focadas na imagem homogêneo, harmônica, coesa e unilateral das Luzes, passaram a considerar a pluralidade de nuances com as quais o ideário iluminista se manifestou nos diferentes contextos cultural e geográfico. (CARVALHO, 2008, p. 31)

A partir da década de 1970, pesquisadores começaram a dar maior atenção às diferenças e às tensões existentes no âmbito do pensamento do século XVIII. Desde então, tem sido publicado vários estudos sobre as especificidades do movimento iluminista em diversos contextos culturais. É significativo o relativo abandono de um tipo de interpretação que privilegia o contexto francês. $O$ historiador norteamericano questiona a associação do Iluminismo aos homens de letras de Paris. (KIRSCHNER, 2009, p. 292) 


\subsection{O caso do Iluminismo português}

Nesta subseção, focaremos um exemplo claro que, em estudos futuros mais aprofundados, pode vir a comprovar a existência da pluralidade de iluminismos: o Iluminismo português, o qual, assim como o Iluminismo alemão, foi interpretado de forma equivocada.

O Iluminismo português foi um movimento tardio em relação a outras manifestações iluministas, por causa da predominância do ensino jesuítico nas universidades e nas escolas, tendo o tomismo como a base ideológica da educação (equilíbrio entre razão e fé).

Por isso, havia uma forte resistência por parte de alguns intelectuais portugueses em relação às novas ideias filosóficas que estavam surgindo na Europa e penetravam em Portugal no final do século XVII. Essas ideias eram contrárias à e diferentes da tradição jesuítica. Além disso, algumas ideias eram consideradas subversivas pela Igreja Católica e, assim, criticadas pelos intelectuais. A formação do Iluminismo português foi, portanto, diferente do de outros países, como a França, em que as ideias racionalistas e da filosofia moderna já tinham se disseminado em alguns grupos. Conforme Kirschner (2009):

a filosofia moderna que já circulava na Europa desde fim do século XVII, ao alcançar Portugal, encontrou uma reação por parte dos defensores da tradição jurídica e filosófica fundamentada no tomismo. Enquanto os demais países europeus se abriam para novas formas de pensar a realidade 
natural e moral, Portugal permaneceu sob o domínio de um ensino jesuítico avesso a especulações filosóficas estranhas à tradição. Tudo que pudesse ser considerado ofensivo à fé católica não encontrava boa acolhida. (KIRSCHNER, 2009, p. 296).

Por isso, o movimento iluminista português começou de uma maneira significativa tardiamente, somente a partir de 1772, com a reforma da Universidade de Coimbra, feita pelo Marquês de Pombal. Kirschner (2009) considera que a reforma oficializou a entrada das ideias ilustradas em Portugal e tinha como principal objetivo garantir a educação iluminista para os futuros funcionários régios. Para isso, o Marquês de Pombal diminuiu o campo de influência da Igreja Católica na administração do Estado e aumentou o poder administrativo do rei. Nas palavras de Kirschner:

embora o ambiente intelectual português tenha se renovado a partir do inicio do século XVIII e o impacto da obra de Antonio Verney tenha sido importante em pequenos grupos da sociedade, foi a reforma da Universidade de Coimbra, em 1772, que, por assim dizer, oficializou a entrada das idéias ilustradas em Portugual. Concebida no âmbito de um projeto de governo que pretendia fortalecer a autoridade régia $\mathrm{e}$ enfraquecer a interferência da Igreja em assuntos temporais, a reforma do ensino universitário tinha como objetivo assegurar uma formação ilustrada para futuros funcionários régios. (2009, p. 298) 
Entretanto, a reforma não teve um caráter anticatólico, diferentemente do que ocorreu em outros países europeus em que foram feitas inúmeras críticas à Instituição católica. Nesses países, os pensadores consideravam que a Igreja não se utilizava de elementos racionais para explicar os acontecimentos ocorridos no passado e no presente. Os pensadores estrangeiros avaliaram os valores da Igreja como um limitador do conhecimento humano e da razão humana, dois temas que estavam em voga na época.

Uma das características marcantes do Iluminismo português, e que difere dos demais movimentos iluministas europeus, é a relação harmônica entre a razão e fé, ou seja, os intelectuais ligaram e complementaram duas ideias opostas: a razão moderna e o princípio da origem. Kirschner (2009) propõe as seguintes hipóteses:

O iluminismo português não adquiriu uma feição antireligiosa e Portugal permaneceu fiel à defesa da fé e da Revelação.

Embora os estatutos da universidade tenham retirado o ensino da filosofia moral da Faculdade de Teologia, isto não traduziu uma ruptura com a tradição tomista. Tratava-se apenas de reconhecer a validade de cada plano naquilo que lhe era próprio. Tanto no que se refere ao direito natural, quanto à ética, reconheciam-se os limites do racionalismo. Ambos necessitavam do apoio, ou do complemente, da Revelação para suprir a falibilidade da razão humana. 
O Iluminismo em Portugal articulou a razão moderna, a filosofia experimental e o princípio da origem e do fundamento divinos do direito natural. A lei era promulgada diretamente por Deus, e a lei natural, em última análise, também de natureza divina, consistia naquilo que os homens podiam acessar por meio da razão e,assim, conhecer o bem.

O princípio sobre o qual se assentava o iluminismo português - a complementaridade entre fé e razão -, foi defendido também, sob distintas perspectivas, por filósofos católicos e protestantes em toda a Europa, e constituiria o núcleo da apologética cristão.

A base do tomismo - a harmonia entre a razão e a fé permaneceu intocada. Uma peculiar articulação das novas idéias à antiga tradição caracteriza o iluminismo português. Questões como a natureza intrinsecamente social do homem, a necessidade da Revelação para complementar as limitações da razão humana e a origem e fundamento divinos do direto natural eram aceitas sem questionamentos em Portugal setecentista. (KIRSCHNER, 2009, p. 198-299)

Além dessa característica marcante do Iluminismo português, este movimento também apresentou outros aspectos que divergiam dos demais movimentos iluministas da época, como o distanciamento das questões sobre o deísmo, feita por Voltaire, e o ceticismo, feita por David Hume, pois os pensadores portugueses enxergavam falhas existentes nas ideias sobre o deísmo e o ceticismo. Por isso, em Portugal, esses temas religiosos sobre o deísmo, ateísmo 
e ceticismo não tiveram a mesma repercussão e polêmica que foi gerada na França, no século XVIII. Para Kirschner (2009):

Em Portugal, o ambiente intelectual da segunda metade do século XVIII não se caracterizou pela existência de fortes polêmicas intelectuais como na França. Passadas as reações provocadas pelas idéias de Antonio Verney e à própria reforma da universidade, não havia dúvidas, para a maior dos ilustrados portugueses, quanto à inconsistência das idéias deístas e da religião natural.

Se o deísmo de Voltaire, o ateísmo de Holbach e de Helvetius, ou o ceticismo de David Hume forem tomados como parâmetros do pensamento filosófico europeu do século XVIII, o panorama intelectual português da segunda metade do século XVIII parece muito distante das Luzes. Entretanto, esses autores não poderiam ser considerados representativos do movimento intelectual europeu com um todo. A crise do pensamento europeu não foi tão demolidora da tradição. (KIRSCHNER, 2009, p. 299)

Devido a esses fatores apresentados, não podemos afirmar que o Iluminismo português teve as suas características iguais aos outros movimentos iluministas. Como também, não podemos afirmar que os iluministas portugueses não apresentaram nenhuma peculiaridade e singularidade em relação aos franceses, pois o movimento português tinha um objetivo em comum com o Iluminismo francês, que era a valorização da razão. 
Por fim, com início da Revolução Francesa, em 1789, recomeçaram a surgir correntes de pensamentos contra o movimento iluminista, os chamados contra revolucionários, e em Portugal a presença deles foi mais acentuada, pois vários teóricos da época associaram, de forma equivocada, o Iluminismo com a Revolução Francesa. Os teóricos afirmavam que os iluministas, de uma maneira geral, tinham o conhecimento que a Revolução Francesa aconteceria, e nada fizeram para "evitar" a Revolução. Com isso, os contrarrevolucionários criticaram com veemência o Iluminismo e as suas respectivas ideologias, relacionando-as ao movimento jacobino francês. E também, os contrarrevolucionários consideravam que os adeptos da Revolução Francesa, os deístas, dentre outros, seriam traidores que alvejavam tomar o trono português. Esse movimento anti-iluminista é relatado por Kirschner (2009):

A eclosão da Revolução Francesa alteraria esse quadro, consistindo um fator decisivo para a radicalização dos debates no ambiente intelectual europeu, ao associar, difusamente, os filósofos à Revolução. A "tragédia revolucionária” seria uma prova dos perigos que podiam advir da imprensa filosófica.

O discurso contra-revolucionário suscitou uma reinterpretação do passado, radicalizou a crítica aos filósofos e atribuiu-lhes a responsabilidade pelo terror desencadeado pela revolução. Abade Barruel, chegou a afirmar que a revolução fora previamente meditada e prevista pelos "filósofos" e ficou conhecido como teórico do "complô". Embora reducionista e superficial, essa representação que 
associou o Iluminismo à Revolução foi poderosa e conveniente. Não é o caso de apontar aqui as incorreções de interpretações e simplificações nelas contidas. O que importa é que ela foi vivenciada pela maior parte das elites europeias como uma verdade praticamente indiscutível. Os adeptos da Revolução, por sua vez, também reinterpretaram o passado, e nele os filósofos ocuparam um lugar positivo de destaque. Ambas as representações tiveram seus porta-vozes na República das letras, repercutiram em tendências historiográficas e produziram efeitos sobre as práticas políticas no fim do século XVIII e ao longo do século XIX.

Para os contra-revolucionários em geral, o termo "filósofo" passou a ser identificado com jacobino, o que contribuiu para a elaboração de uma das correntes historiográficas sobre as causas da Revolução.

A idéia do Iluminismo como causa da revolução teve ampla acolhida em Portugal. Voltaire, Rousseau, Raynal e Mably foram considerados autores perigosos e a circulação de suas obras foi proibida.

Deístas, defensores da religião natural e, agora, simpatizantes da Revolução, formavam uma legião de traidores que ameaçavam o trono e o altar. A palavra filósofo sinalizava perigo. (KIRSCHNER, 2009, p. 300-301)

A partir do movimento anti-iluminista e do movimento que igualava o Iluminismo com a Revolução Francesa do final do século XVIII e início do século XIX, teremos novas formas de historiografia e de administração política no decorrer do século XIX e XX, como 
Kirschner (2009) relatou. E umas das consequências trazidas pela associação do Iluminismo com a Revolução Francesa foi a homogeneidade do movimento iluminista, centrado na França e nos filósofos franceses, ou seja, o assunto que permeou esse trabalho nasceu dessa relação entre o Iluminismo e a Revolução Francesa.

\section{Conclusão}

Com esse trabalho tentamos desmistificar a existência de um conceito singular do Iluminismo, cujo foco está voltado para a França e para os pensadores franceses. Para isso, utilizamos do Iluminismo português com o objetivo de demonstrar que existiu mais tipo de movimento intelectual do século XIII.

Além disso, fizemos uma análise do conteúdo do Iluminismo em um livro didático para termos uma noção de como o tema é ensinado nas salas de aula. Deparamo-nos com um conteúdo falho e limitado para a verdadeira contribuição do conhecimento do século XVIII e as suas manifestações intelectuais para o século XXI. Essa limitação também foi percebida em duas questões de vestibular.

Depois da análise do ensino do Iluminismo no ensino médio, tentamos definir o que foi o movimento iluminista $\mathrm{e}$ as suas consequências para o mundo. Mesmo sabendo que existiu mais de um tipo de Iluminismo, fizemos um apanhado geral das características gerais presentes nos movimentos intelectuais, principalmente no francês e no português. 
Esperamos que, com esse trabalho, que de modo algum se encerra aqui, ter mostrado que o Iluminismo é um tema extremamente rico e que deve ser tratado com mais profundidade nas escolas e no material didático.

Para o futuro, pretendemos ampliar ainda mais esse debate, levando-o, na prática, para a sala de aula e, quem sabe, despertar nos alunos o gosto pelo estudo dos movimentos iluministas.

\section{Referências bibliográficas}

BRASIL. Secretaria de Educação Fundamental. Parâmetros curriculares nacionais : história, geografia / Secretaria de Educação Fundamental. - Brasília :MEC/SEF, 1997. Disponível em http://portal.mec.gov.br/seb/arquivos/pdf/livro051.pdf, com aceso em 26/08/2013.

BRASIL. Secretaria de Educação Básica. Ciências humanas e suas tecnologias / Secretaria de Educação Básica. - Brasília: Ministério da Educação, Secretaria de Educação Básica, 2006.

Disponível

em http://portal.mec.gov.br/seb/arquivos/pdf/book_volume_03 internet.pdf, com acesso em 26/08/2013. (Orientações curriculares para o ensino médio ; volume 3 ) 
CARVALHO, F. R. Um Iluminismo português? A reforma da Universidade de Coimbra (1772). São Paulo: Annablume, 2008.

CASSIRER, E. A filosofia do Iluminismo. Campinas: Unicamp, 1997.

COSTA, E. V. A invenção do Iluminismo. In: COGGIOLA, O. (org.). A Revolução Francesa e seu impacto na América Latina. São Paulo: Nova Stella Editorial, 1990.

DARTON, R. Os dentes falsos de George Washington: Um guia não convencional para o século XVIII. São Paulo: Companhia das Letras, 2005.

FALCON, F. J. C. Iluminismo. São Paulo: Ática, 2009.

HUNT, L. A invenção dos direitos humanos: Uma história. São Paulo: Companhia das Letras, 2009.

KIRSCHNER, T. C. Itinerários de um ilustrado luso-brasileiro. São Paulo: Alameda Casa Editorial, 2009.

ROUANET, S. P. Razões do Neo-Iluminismo. In: Cornelius Castoriadis et ali. A criação histórica. Porto Alegre: Ofícios, 1992.

PEDRO, A.; LIMA, L. de S.. História da civilização ocidental. São Paulo: FTD, 2004. 